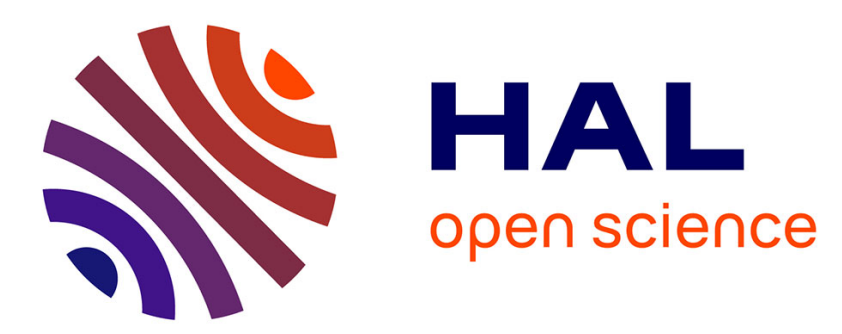

\title{
Modelling of massive bedload deposition in a debris basin: cross comparison between numerical and small scale modelling
}

Matthieu Gonzales de Linares, Vincent Mano, Guillaume Piton, Alain Recking

\section{- To cite this version:}

Matthieu Gonzales de Linares, Vincent Mano, Guillaume Piton, Alain Recking. Modelling of massive bedload deposition in a debris basin: cross comparison between numerical and small scale modelling. RiverFlow 2020, Jul 2020, Delft, Netherlands. hal-02935173

\section{HAL Id: hal-02935173 \\ https://hal.science/hal-02935173}

Submitted on 10 Sep 2020

HAL is a multi-disciplinary open access archive for the deposit and dissemination of scientific research documents, whether they are published or not. The documents may come from teaching and research institutions in France or abroad, or from public or private research centers.
L'archive ouverte pluridisciplinaire HAL, est destinée au dépôt et à la diffusion de documents scientifiques de niveau recherche, publiés ou non, émanant des établissements d'enseignement et de recherche français ou étrangers, des laboratoires publics ou privés.

\section{(c)(1)}

Distributed under a Creative Commons Attribution| 4.0 International License 


\title{
Modelling of massive bedload deposition in a debris basin: cross comparison between numerical and small scale modelling
}

\author{
M. Gonzales de Linares \\ ARTELIA, Echirolles, France
}

V. Mano

ARTELIA, Echirolles, France

G. Piton

Univ. Grenoble Alpes, INRAE, ETNA, F-38402 St-Martin-d'Hères, France

\author{
A. Recking \\ Univ. Grenoble Alpes, INRAE, ETNA, F-38402 St-Martin-d'Hères, France
}

\begin{abstract}
A small-scale physical model was build and used to study deposition processes in a planned debris basin in the French Alps. Numerical simulations were then undertaken with a 2D depth-averaged hydraulic and morphologic numerical model in order to check its capability to reproduce flow and bed changes in this steep and laterally unconfined case with coarse sediment. The paper focuses on the set-up of the numerical model, which enables to get results very similar to the physical model. Old and state-of-the-art formulations for friction law and for bedload transport equation were compared. More precisely, the best performance were obtained with a friction law valid for small relative flow depth and bedload transport formulation using a nonthreshold equation.
\end{abstract}

\section{INTRODUCTION}

In mountain and piedmont regions, flood hazards are not only driven by high water discharges but also by the amount of sediment delivered to the area at risk and eventually depositing and obstructing river channels.

On Aug. $21^{\text {st }}$ and $22^{\text {nd }}, 2005$, long lasting and intense rainfall on the Belledonne mountain range (France) triggered debris floods in several catchments, i.e., flood events transporting large amount of bedload down to the valley. The Combe-de-Lancey Stream for instance experienced debris flows in its headwaters as well as heavy bank erosion in its mid catchment part. It finally deposited $20,000 \mathrm{~m}^{3}$ of bedload material in the city of Villard-Bonnot that occupies the alluvial fan. A comprehensive study was recently performed to define a protection strategy. It demonstrated that a debris retention basin was the relevant solution to trap and store the bedload supply because the stream cannot transport it further due to its mild slope and limited channel capacity. A small-scale model was build and used to study how the deposition processes occur in the planned debris basin under various debris flow scenarios (Piton et al., 2019a, Horiguchi et al., 2020).

The objective of the numerical study presented here is to check how a 2D numerical morphological model performs in computing the hydrosedimentary processes in such a case. Specificities of this case related to the numerical simulation are notably the high slopes $(1 \%-8 \%)$, near critical flows and very coarse particle sizes. It was an opportunity, using small-scale model results as reference, to define the methods and parameters of calculation necessary to achieve satisfying results. Several friction laws and sediment transport equations were tested and validated - or not - against the small-scale model results. 


\section{PHYSICAL MODEL}

\subsection{Design}

A physical scale model was built and operated in order to design a retention basin and an associated open check dam to secure the city of Villard Bonnot.

The scale of the model was 1:40. The model was built to satisfy the Froude similitude and the granulometry was defined to satisfy the Shields similitude, in order to accurately represent both hydraulics and sediment transport processes. The median diameter $\left(D_{50}\right)$ of the mixture used in the physical was $1.2 \mathrm{~mm}$ (47 $\mathrm{mm}$ real size).

Representative liquid and solid hydrographs were introduced into the model. Water supply was ensured by a gate and controlled with an electromagnetic flowmeter. Sediment supply was applied upstream using a calibrated feed hopper. The experimental run studied in the present paper corresponds to a short duration project design event (i.e. having a $\sim 1: 100$ years return period for liquid and solid discharge): influx of sediment of $20000 \mathrm{~m}^{3}$, liquid peak discharge of $35 \mathrm{~m}^{3} / \mathrm{s}$, duration of about 10 hours (see figure below).

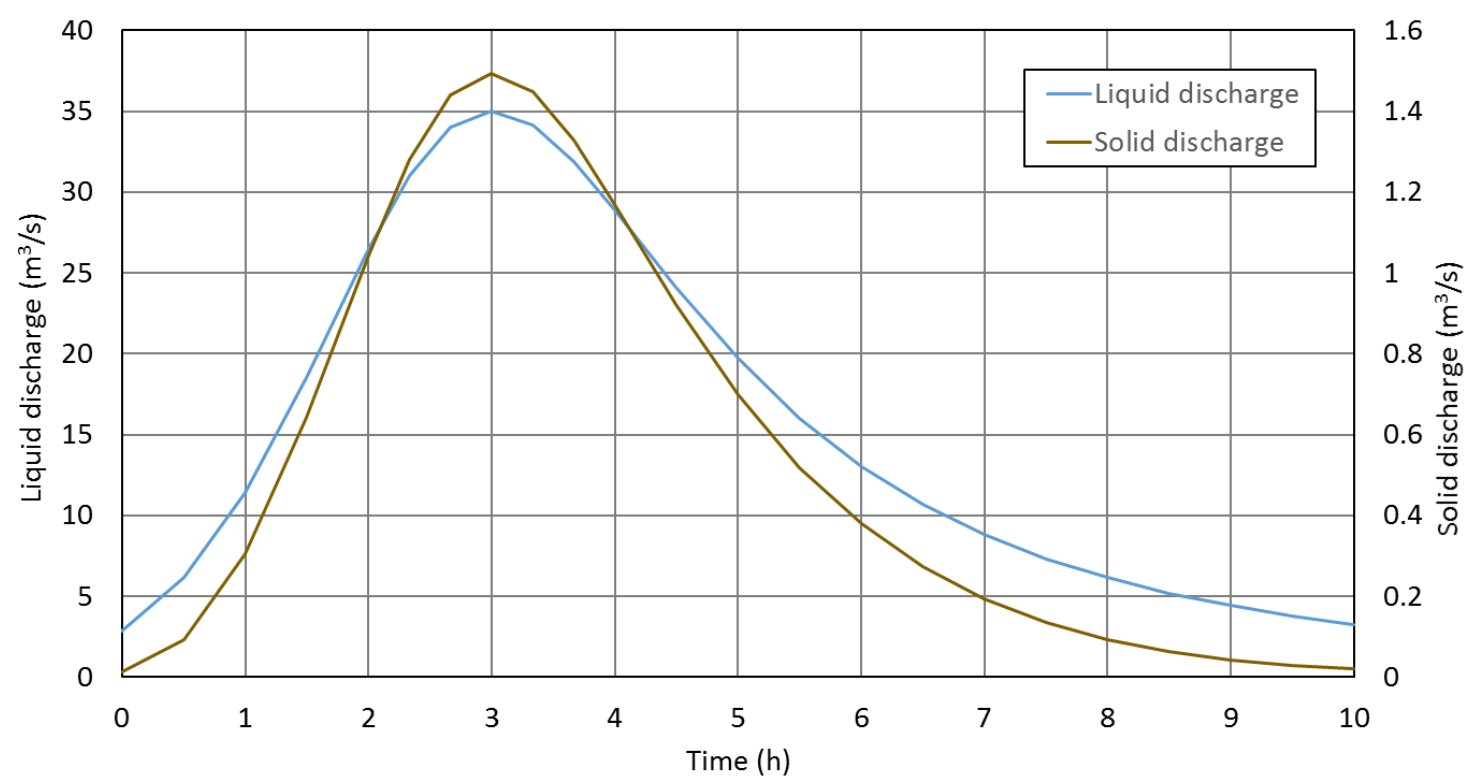

Figure 1. Upstream boundary conditions (prototype scale) for the chosen test

Water levels were measured at the downstream open check dam, whereas several surface velocity fields were measured using LSPIV (Large Scale Particle Image Velocimetry) method. Time-lapse photographs were made to assess sediment deposition and sediment transport processes occurring during the tests. Final sediment deposits in the basin were monitored with photogrammetry method.

Other papers describe how the open check dam closing the debris basin was adapted in order to ensure satisfying trapping of large wood pieces (Piton et al., 2019a and Horiguchi et al., 2020). Here we focus on the deposition pattern observed in basin upstream of the open check dam.

\subsection{Observations from small-scale model used as references}

The main observed phases of deposition are illustrated in Figure 1: A pool rapidly appeared at the downstream part of the basin because of the backwater effect of the open check dam. Large wood clogged the openings aggravating the flooding of the basin nearly up to the inlet area. Sediment spread near the inlet in an alluvial fan pattern. A very steep front formed at the head of the deposit when entering the flooded basin area. This delta pattern prograded by forming lobes in the flooded basin along all the run (Figure 1b, d, f). The fulcrum point between the steep delta front and the alluvial fan overtopping it settled near the free surface level. At the peak of the hydrograph, the 
open check dams was largely overtopped (Figure 1c) and the deposit only partially filled the basin (Figure 1d). During the flood recession, flow level decreased and the deposit prograded more rapidly, filling the basin nearly down to the open check dam location. An area located beyond the open check dam on the right bank was filled only by fine material transported in suspension. A photogrammetry acquisition of the final deposit enabled detailed topographical measurement. The top slope of the deposit, i.e., the alluvial slope of the fan, was measured at 7.5\% $\pm 0.8 \%$ (mean \pm standard deviation measured on the five profiles displayed in Figure 2a).
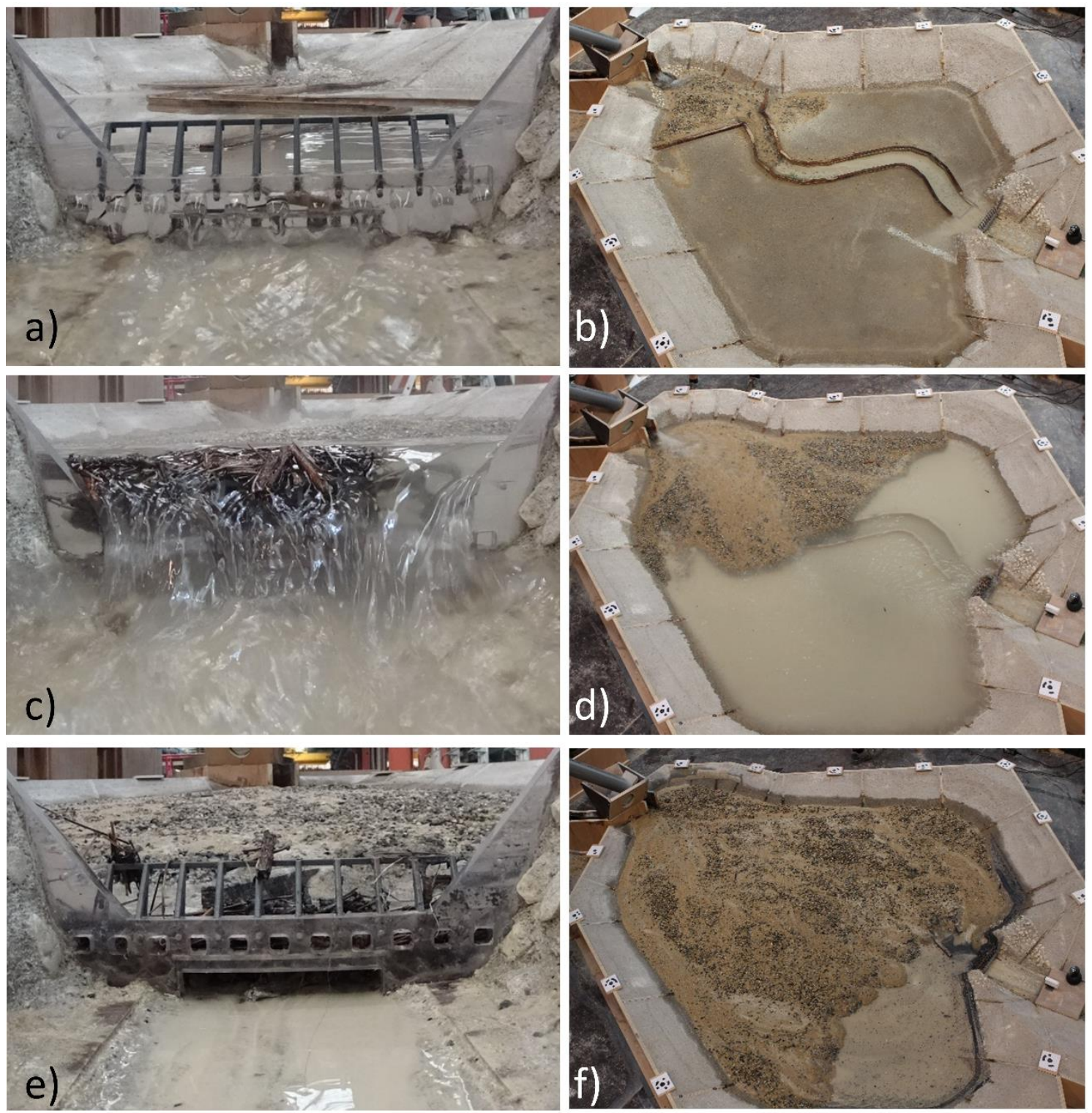

Figure 2. Downstream and side view of the small scale model filling: a) \& b) beginning of the run, c) $\&$ d) peak of the hydrograph and e) \& f) end of the run

\section{METHOD}

\subsection{Software used}

The numerical model is based on the TELEMAC open-source system : TELEMAC 2D (solving of shallow-water equations) coupled with SISYPHE (sediment transport and bed evolution, see Villaret et al. 2013). Coupling is done at each time step, thus hydrodynamics take into account changes of bed elevation at each time step. 


\subsection{Mesh and bathymetry}

The numerical model was run on an unstructured grid of triangular elements. Different mesh resolutions were tested. Results for the finest mesh size, i.e. 5 millimeters, are presented in this paper The initial bathymetry of the model (Figure 3a) was representative of the concrete bottom of the physical scale model visible on Figure $2 b$.

\subsection{Forcings}

The forcings of the model consisted in non-stationnary liquid and solid boundary conditions (Figure 1) representative of the physical test chosen to be simulated with the numerical model (see 2.1). Water depth at the downstream boundary (i.e. the open check dam) was directly imposed based on measurements, and thus took into account the effect of trapped wooden debris. For numerical stability reasons, the upstream solid boundary conditions was not imposed as a solid discharge in the upstream boundary, but rather as a bed evolution of the upstream inlet channel.

\subsection{Hypothesis}

Different friction laws, and bedload transport formulas were tested.

\subsubsection{Friction laws}

Two friction laws were tested. The Manning-Strickler formulation was tested along with the variable power equation proposed by Ferguson (2007), which is supposed to be more adapted for steep slopes flows (Rickenmann \& Recking 2011).

The estimation of the value of the Strickler coefficient can be made (following Ferguson, 2007) based on a representative grain size ( $D_{50}$ or $D_{84}$, considering the sediment mixture entering the model), or estimated by integration of the logarithmic law (so called Keulegan approach) and considering a roughness length of three times the $D_{50}$, and water heights around one centimeter. A constant Strickler coefficient of $60 \mathrm{~m}^{1 / 3} / \mathrm{s}$ was chosen as a compromise between the different values estimated as above.

The parameter of the friction law by Ferguson (2007) is $D_{84}$ (here $3 \mathrm{~mm}$ ), thus no prior estimation of the friction coefficient was necessary for this friction law.

\subsubsection{Bedload transport formulas}

Two bedload transport equations were also tested: the Meyer-Peter and Müller (1948) formulation and the Recking et al. (2016) non-threshold formulation adapted to steep slopes.

The Meyer Peter \& Muller equation is a threshold equation and the original equation considers a critical Shields parameter equal to 0.047 , and a specific procedure to compute grain shear stress. Based on the experience of one of the authors, we made the hypothesis that the total shear stress is applied to the grains (no prior computation of grain shear stress is thus necessary), and the critical Shields parameter is equal to 0.035 . This equation thus writes:

$$
\Phi \propto\left(\tau^{*}-0.035\right)^{1.5}
$$

With $\Phi$ the dimensionless solid discharge and $\tau^{*}$ the dimensionless shear stress based on total shear stress.

Because our observations did not clearly show a correspondence between the flow intensity and sediment transport we also tested a non-threshold equation. We used the Recking et al (2016) equation as it had yet been tested for steep slopes. Because the equation was used in a 2D code and must calculate the local transport for the local shear stress, we did not use the field derived reach average equation but rather the flume version for local transport (Recking et al., 2016) which writes:

$$
\Phi=14 \frac{\tau^{* 2.5}}{1+\left(\frac{\tau_{m}^{*}}{\tau^{*}}\right)^{10}}
$$


With $\tau_{m}^{*}$ a mobility dimensionless shear stress. Recking et al. (2016) proposed to compute this parameter as a function of slope $S$ with $\tau_{m}^{*}=0.26 S^{0.3}$. In our case, a constant value of this mobility dimensionless shear stress of 0.065 (corresponding to a slope of $0.015 \mathrm{~m} / \mathrm{m}$, i.e., the bottom slope of the deposition basin) was used.

\section{RESULTS}

\subsection{General comparison of filling phases}

Visual comparison between time-lapse videos of the experiments and numerical results demonstrated that the deposit dynamics and main phases were correctly represented by the numerical model. Whatever the friction and the transport equations, bedload material spread at the basin inlet and only slowly progressed in the basin. At peak flow, only part of the basin was filled (graphs not shown here). At the end of the run, most of the bedload was trapped by the basin. The downstream area located on the right bank was empty (Figure 3c-f), consistently with the experimental results (Figure $3 \mathrm{~b}$ ). The steep delta front forming in the pool area was correctly computed in all numerical runs. When looking more in details, divergences appear between numerical formulations and more generally between numerical results and experiments.

\subsection{Filling pattern}

It is first observed that both runs using the Manning friction law resulted in deposits that preferentially filled the left bank (Figure $3 \mathrm{c} \&$ e); while the deposit prograded in a more homogeneous front in both runs using the Ferguson friction law (Figure 3d \& f). The left-bank preferential flow resulted from the inlet structure oriented in this direction. The Armor Breaking experimental run we compare here to numerical result experienced too a slight preferential deposit to the left bank at peak flow (Figure 2d), though not as high as in the numerical model (results not shown here). At the end of the experiment, the deposit had a nearly homogeneous shape (Figure 2b) that was correctly captured by both runs using Ferguson friction law (Figure $3 \mathrm{~d} \& \mathrm{f}$ ). Flow was observed to wander on the deposit in single and multi-thread channels during all experiments. The numerically simulated channel mobility was not as high as the experimental one.

\subsection{Deposition slope}

The next observation is related to deposit slope (Table 1). It can be observed that in the experiment, deposit settled at a slope of about 7.5\% resulting in elevation of 1.94-1.96 m in the laboratory elevation system (dark blue color in Figure 3b). Numerical results using the Meyer-Peter \& Mueller transport both underestimated the deposit slope and thus upstream elevation. The transport efficacy was too high resulting in excessively mobile bedload material that spread slightly too far in the basin or were exported (Figure 3c-d) and underestimated slopes (Table 1). Conversely, using the Recking et al. transport formula along with the Manning friction law resulted in very steep deposit (slope $\approx 10 \%$ ) that only partially filled the basin and was very different from the experiment (Figure 2e). Interestingly, using both the more up-to-date friction law, i.e., Ferguson's, and transport equation, i.e., Recking et al.'s, resulted - without tuning of both formulation - in a deposit pattern (compare Figure $3 \mathrm{~b} \& \mathrm{f}$ ) and in deposit slope of about $7.6 \%$ surprisingly close from the experiment $7.5 \%$. This is an interesting evidence of the relevance to encapsulate friction laws able to deal with high roughness and non-threshold sediment transport equations in 2D numerical models of steep slope streams.

Table 1. Deposition slopes on the 5 measurements along profiles of Fig. 2a.

\begin{tabular}{lccccc}
\hline Run* & Flume & Mann.+MPM. & Ferg.+MPM. & Mann.+Reck. & Ferg.+Reck. \\
\hline Mean \pm Std. Dev. [\%] & $7.5 \pm 0.8$ & $4.6 \pm 1.4$ & $5.6 \pm 0.9$ & $9.7 \pm 1.9$ & $7.6 \pm 0.8$ \\
\hline *Mann. for Manning friction law, MPM. for Meyer Peter and Mueller transport law, Ferg. for Ferguson \\
friction law and Reck. for Recking et al. transport law
\end{tabular}




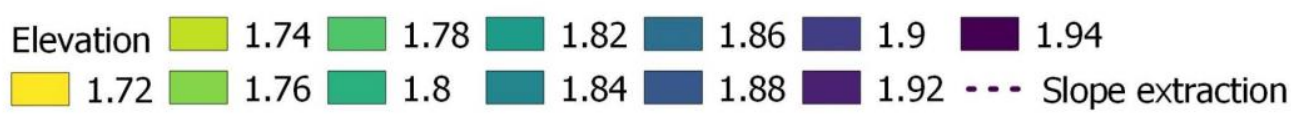

Small scale model 1:40 (ARTELIA laboratory)

a) Initial state

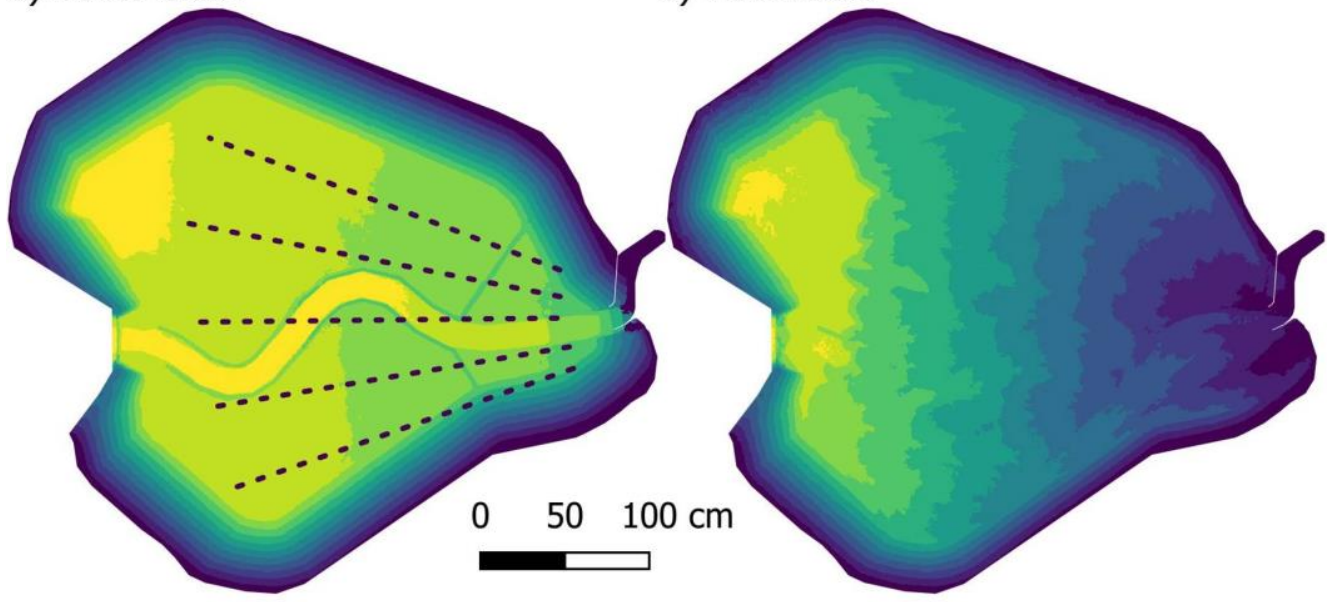

Numerical model (Telemac 2D - Sisyphe)

c) Manning + Meyer Peter \& Mueller d) Ferguson + Meyer Peter \& Mueller

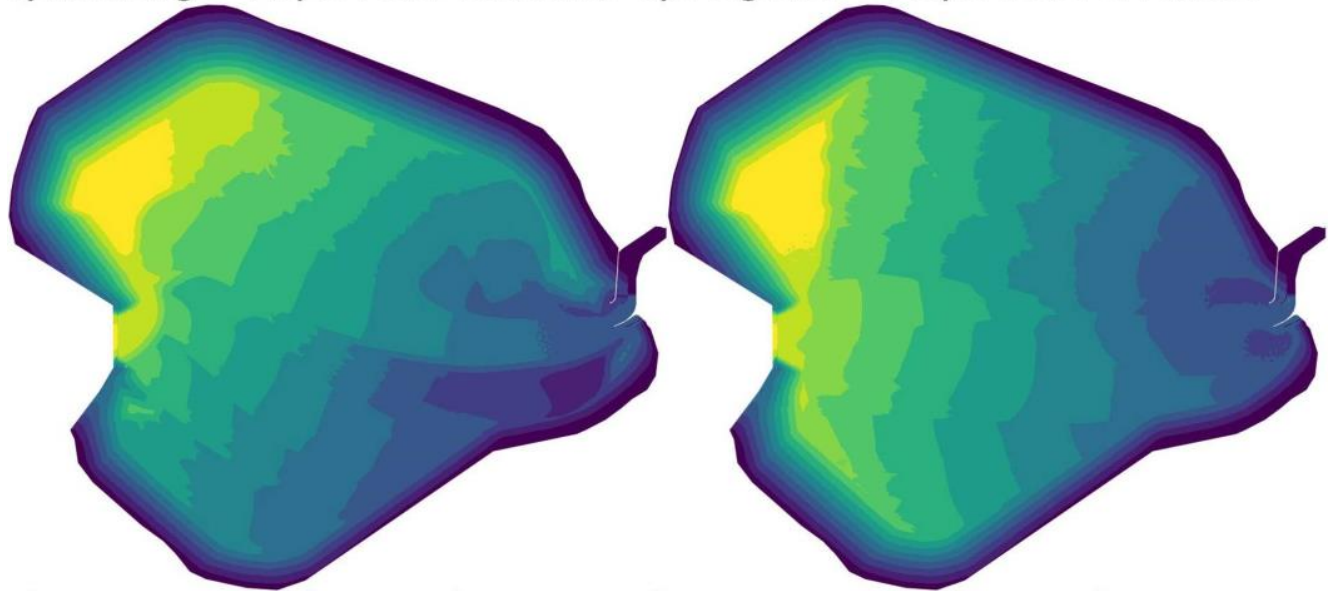

e) Manning + Recking et al.

f) Ferguson + Recking et al.

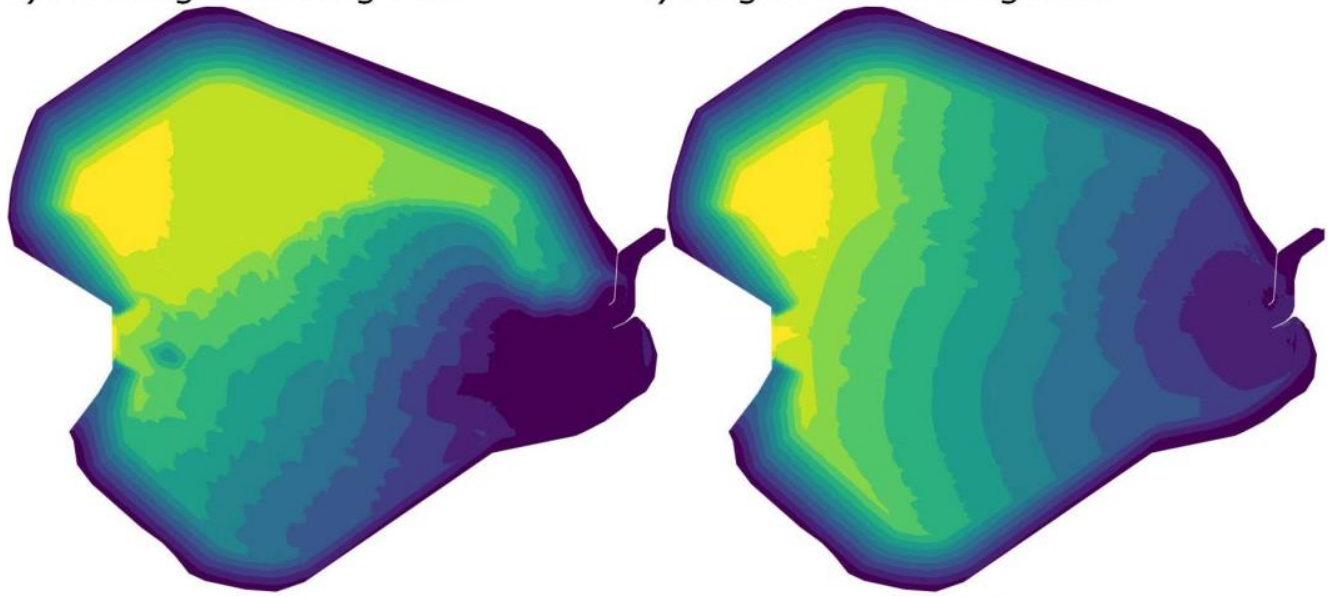

Figure 3. Digital elevation model of the physical model: a) Initial state, b) finale state; numerical model result in final state using c) Manning friction law, MPM transport law, d) Ferguson friction law, MPM transport law, e) Manning friction law, Recking et al. transport law, f) Ferguson friction law 


\section{DISCUSSION}

A relevant numerical modelling of the deposit slope is critical in the design of debris basin because it strongly controls the trapping efficacy (Piton and Recking, 2016). Defining its value remains partially an open question when designing structures in data-scarce context. Here, detailed measurements were available from the experimental campaign and it was a unique opportunity to check the capability of numerical models to compute correctly both the spreading pattern and the deposit slope.

Encapsulating relevant formulation of both friction laws and bedload transport proved to have significant effect on the numerical results. Further work using LSPIV data is in progress, with the aim of providing intermediate validation of the friction law.

Well-defined and highly mobile channels were observed during the experiments. Efficient grain size sorting, along with processes of armoring and armor breaking or diversion of channel after formation of coarse grain clusters were systematically observed in the physical model as in Piton et al. $(2018,2019 b)$. Such processes obviously cannot be capture in the single grain size formulation used in TELEMAC 2D-SISYPHE in the present work. When looking more precisely in the numerical model results, we observed overestimation of flow spreading and underestimation of self-channelization and channel wandering observed in the experiment. We suspect that grain segregation enhanced strongly this process. Future work on this model (this time using GAIA, the up-to-date morphological model of the TELEMAC system, instead of SISYPHE) will therefore cover the accounting of poorly sorted grain size distribution.

Validation will then be attempted on other runs of the physical model, in order to improve the confidence on the formulations used.

\section{CONCLUSION}

TELEMAC 2D and SISYPHE coupled are able to compute very satisfactorily the bed evolutions of a run of a physical model with high sediment load and steep slopes. These results validate new formulations recently proposed for friction law in the case of high relative roughnesses, and bed load transport for steep slope.

\section{REFERENCE}

Ferguson, R. 2007. Flow resistance equations for gravel-and boulder-bed streams. Water Resources Research 43:1-12. DOI: 10.1029/2006WR005422

Horiguchi, T.; Piton, G.; Munir, M. \& Mano, V. 2020. Driftwood and Hybrid Debris Barrier Interactions: Process of Trapping and Prevention of Releases during Overtopping. In Proc. of the 14th INTERPRAEVENT Congress. May $11^{\text {th }}-14^{\text {th }}$, Bergen - Norway. 1-11

Meyer-Peter, E; Müller, R. 1948. Formulas for bed-load transport. In Proc. of the $2^{\text {nd }}$ Meeting of the International Association for Hydraulic Structures Research, 39-64 pp.

Piton, G. \& Recking, A. 2016 Closure to "Design of Sediment Traps with Open Check Dams. I: Hydraulic and Deposition Processes" by Guillaume Piton and Alain Recking, Journal of Hydraulic Engineering, 142(10):07016009, DOI: 10.1061/(ASCE)HY.1943-7900.0001207

Piton, G; Mano, V; Richard, D; Evin, G; Laigle, D; Tacnet, J; Rielland, P. 2019a. Design of a debris retention basin enabling sediment continuity for small events: the Combe de Lancey case study (France). In Proc. 7th Int. Conf. on Debris-Flow Hazards Mitigation, June 10 - 13, 2019 Golden, CO., USA. 10191026.

Piton, G., \& Recking, A. 2019b. Steep bedload-laden flows: Near critical? Journal of Geophysical Research: Earth , 124: 2160-2175. doi10.1029/2019JF005021

Piton, G.; Recking, A.; Le Coz, J.; Bellot, H.; Hauet, A. \& Jodeau, M. 2018. Reconstructing Depth-Averaged Open-Channel Flows Using Image Velocimetry and Photogrammetry, Water Resources Research, American Geophysical Union (AGU), 54(6):4164-4179, DOI: 10.1029/2017WR021314

Recking, A; Piton, G; Vázquez-Tarrío, \& D Parker G. 2016. Quantifying the morphological print of bedload transport. Earth Surface Processes and Landforms 41:809-822. DOI: 10.1002/esp.3869

Rickenmann, D. \& Recking, A. (2011), Evaluation of flow resistance in gravel-bed rivers through a large field data set, Water Resour. Res., 47, W07538, doi:10.1029/2010WR009793 
Villaret, C; Hervouet, J-M; Kopmann, R; Merkel, U; Davies, AG. 2013. Morphodynamic modeling using the Telemac finite-element system. Computers \& Geosciences 53:105-113. 